BENHA VETERINARY MEDICAL JOURNAL, VOL. 34, No. 3: 287-294, AUGUST 2018

A SPECIAL ISSUE FOR THE $6^{\text {TH }}$ SCIENTIFIC INTERNATIONAL CONFERENCE

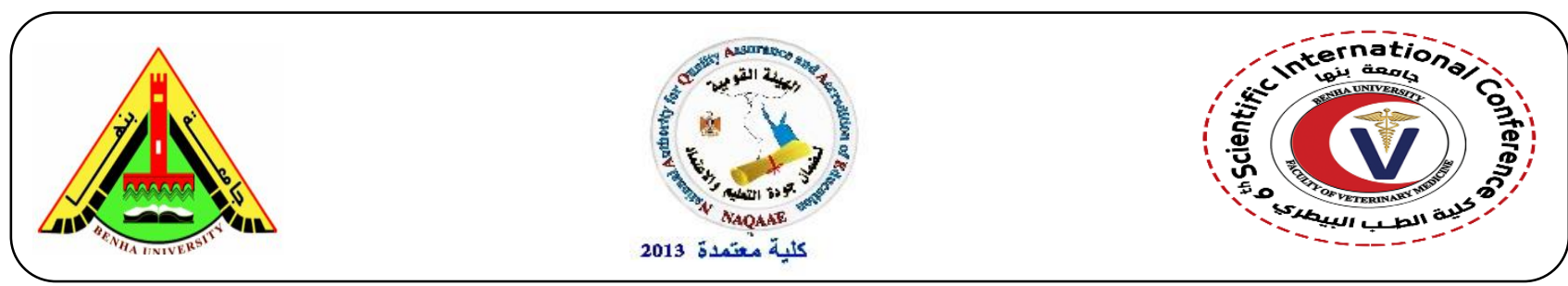

\title{
Hematobiochemical and Urological Alterations in Buffaloes with Post parturient Haemoglobinuria
}

\author{
Hayat Fayed", Ghanem, M. M. , Abdel-Raof, Y. M. and El-Attar, H. M. \\ Department of animal medicine, Faculty of Veterinary Medicine, Benha University, Egypt. \\ Correspondence* (Hayat.Fayed@fvtm.bu.edu.eg)
}

\section{A B S T R A C T}

This study was carried out to estimate the haematological, serum biochemical and urological alterations associated with post parturient haemoglobinuria (PPH) on 70 haemoglobinuria and 30 apparently healthy buffaloes. Blood, serum and urine samples were collected and tested for various haematological, biochemical and urological parameters. Significant decrease in total erythrocyte count, $\mathrm{Hb}$ concentration, $\mathrm{PCV} \%$, lymphocyte $\%$, serum inorganic phosphorus, total protein, albumin, glucose whereas significant increase in neutrophils $\%$, serum urea, creatinine, total bilirubin and alkaline phosphatase. In PPH colour of urine in haemoglobinuria buffaloes ranged from red, dark red to coffee colour. Analysis of urine samples by Reagent urine strips showed positive for haemoglobin and protein. It was concluded that post parturient haemoglobinuria causes severe alterations in hematobiochemical and urological parameters in buffaloes.

Key words: Buffaloes, post parturient haemoglobinuria, haemolytic anaemia, serum biochemistry, urinalysis.

\section{INTRODUCTION}

Phosphorus $(\mathrm{P})$ is a vital mineral that involved in bone growth, animal productivity and most of the metabolic processes of the body. $\mathrm{P}$ is an important constituent of lipids, proteins and nucleic acids (Ternouth, 1990). In ruminant, $\mathrm{P}$ is the most common deficient mineral in many areas of the world. As this nutrient has a complicated metabolism and its deficiency may occur at different levels particularly in animals raise in pasture (NRC, 2001). Dietary 
phosphorus deficiency and feeding cruciferous plants have been incriminated as causes for post parturient haemoglobinuria in ruminant (Constable et al. 2017). PPH is characterized by hypophosphatemia, intravascular haemolysis, haemoglobinuria and anaemia. Hypophosphatemia is a well-known metabolic disorder of cattle and buffaloes resulting from deficiency of phosphorous or imbalance in the $\mathrm{Ca}$ : $\mathrm{P}$ ratio. Insufficiency of phosphorus leads to hypophosphatemia and haemoglobinuria by diminishing RBCs glycolysis and ATP synthesis (Radostits et al., 2003). Parturient haemoglobinuria is a major disease of dairy animals with detrimental economic consequences (Chugh et al., 1996). In PHH significant decrease in erythrocyte count, haemoglobin concentration, haematocrit, lymphocyte count, serum calcium, phosphorous and selenium whereas marked increase TLC, serum alkaline phosphatase and total bilirubin were recorded in haemoglobinuric buffaloes (Mahmood, 2011).

Therefore, this work aimed to evaluate haematological, serum biochemical and urological alterations associated with post parturient haemoglobinuria.

\section{2, MATERIAL AND METHODS Animals}

The study included 70 buffaloes suffering from post-parturient haemoglobinuria that were randomly selected from field cases that occurred in some localities in El-qalyubia governorate from January to May (season of berseem feeding) in 2016 to 2018 . The controls were 30 clinically healthy buffaloes of similar description from the same localities. Animals of the study were feeding on stall fed, and seasonal green fodders, including Trifolium alexandrinum (Berseem).
The disease was clinically diagnosed on the basis of specific clinical signs, such as haemoglobinuria during advanced pregnancy or early lactation. Also, other diseases that cause a reddish discolouration of urine, like babesiosis, leptospirosis, and bacillary haemoglobinuria, were ruled out through laboratory tests.

\subsection{Samples}

1.1.1. Blood samples:

Blood samples were collected from jugular vein according to (Kelly, 1984).

The blood samples were collected in vacutainer tubes with EDTA, used for haematological studies (total erythrocytic count, haemoglobin content, PCV and total leucocytic count).

\subsubsection{Serum samples:}

Blood sample was taken by allowing about $5 \mathrm{ml}$ of blood to flow freely and gently over the inner surface of a clean and dry centrifuge tube. The samples were allowed to clot in slanting position at room temperature for about 2 hours then the samples were centrifuged at 3000 rpm for 10 minutes, the clear sera were aspirated carefully and transferred into clear dry labelled Eppendorf tubes and stored at $-20{ }^{\circ} \mathrm{C}$ till examination. Serum samples were used for the biochemical determination of phosphorus, total protein, albumin, glucose, urea, creatinine, total bilirubin and ALP.

\subsubsection{Urine samples:}

Urine samples were collected from each animal using a sterilized catheter into clean, dry, sterilized brown coloured glass bottles, brought to laboratory immediately and processed for gross and biochemical analysis following the procedures described by (Benjamin, 1978).

\subsection{Laboratory examination \\ 1.2.1. Haematological examination}


The haematological studies including erythrogram and leukogram were evaluated by using automatic cell counter according to (Thrall et al., 2012).

\subsubsection{Biochemical analysis of serum}

The serum samples were used for spectrophotometric determination of Inorganic phosphorus (Anderson and Cockayne, 1993), total proteins (Pagana and Pagana, 2010), albumin (Fischbach and Dunning, 2009), glucose (Trinder, 1969), urea (Patton and Crouch, 1977), creatinine (Young, 1990), total bilirubin (Kaneko et al., 1997) and Alkaline phosphatase (ALP) activity (Patton and Crouch, 1977).

\subsubsection{Urine analysis}

These urine samples were examined for colour, proteins, glucose, blood (haemoglobin) and ketone bodies following the procedures described by (Benjamin, 1978). Urine samples were analysed by Reagent urine strips. Samples of urine were collected and centrifuged to differentiate haematuria and haemoglobinuria.

\subsection{Statistical analysis}

The data were statically analysed using Ttest in the study as previously described by (Bailey, 2008). We used SPSS version 16 software to conduct this analysis. Values were represented as means \pm standard error (SE). All differences were considered significantly among groups of the experimental study when $P \leq 0.05$.

\section{RESULTS}

\subsection{Haematological changes}

In the post parturient haemoglobinuria affected buffaloes, total erythrocyte count, haemoglobin concentration, haematocrit \%, lymphocyte \% were significantly $(\mathrm{p} \leq 0.05)$ lower, while total leukocyte count and neutrophils \% were significantly $(\mathrm{p} \leq 0.05)$ increased than in the healthy buffaloes (Table 1).

\subsection{Biochemical changes}

Inorganic phosphorus, total protein, albumin and glucose in PPH affected buffaloes were significantly $(p \leq 0.05)$ decreased, whereas serum urea, creatinine, total bilirubin and alkaline phosphatase were significantly $(\mathrm{p} \leq 0.05)$ higher than in healthy buffaloes (Table 2).

\subsection{Urine analysis}

The colour of urine in haemoglobinuric buffaloes ranged from red, dark red to coffee colour, depending upon the severity and duration of illness. The samples were positive for haemoglobin (Haemolyzed) is indicated by colour change on urine strips. Urine samples were also positive for proteins. However, samples were negative for glucose, ketone bodies and leucocytes. Urine examination of healthy buffaloes showed that all the parameters were within the normal physiological limits (Figure 1). 
Table (1): Haematological parameters of control and post parturient haemoglobinuria affected buffaloes (Means \pm S.E.).

\begin{tabular}{cccc}
\hline & Control & PPH & P value \\
\hline RBC million $/ \mathrm{mm}^{3}$ & $6.51 \pm 0.18 \mathrm{a}$ & $3.26 \pm 0.11 \mathrm{~b}$ & $<0.001$ \\
\hline $\mathrm{Hb}$ g/dl & $11.08 \pm 0.25 \mathrm{a}$ & $6.11 \pm 0.13 \mathrm{~b}$ & $<0.001$ \\
\hline $\mathrm{PCV} \%$ & $34.56 \pm 0.46 \mathrm{a}$ & $17.86 \pm 0.24 \mathrm{~b}$ & $<0.001$ \\
\hline WBC thousand $/ \mathrm{mm}^{3}$ & $8.55 \pm 0.21 \mathrm{~b}$ & $10.01 \pm 0.15 \mathrm{a}$ & $<0.001$ \\
\hline Neutrophils \% & $33.99 \pm 1.26 \mathrm{~b}$ & $43.89 \pm 0.83 \mathrm{a}$ & $<0.001$ \\
\hline Lymphocyte \% & $55.94 \pm 1.43 \mathrm{a}$ & $49.09 \pm 0.49 \mathrm{~b}$ & $<0.001$ \\
\hline
\end{tabular}

-Values with different superscript letters within the same row were statistically significant at $p<0.05$.

Table (2): Biochemical analysis of control and post parturient haemoglobinuria affected buffaloes (Means \pm S.E.).

\begin{tabular}{cccc}
\hline & Control & PPH & P value \\
\hline P mg/dl & $5.44 \pm 0.21 \mathrm{a}$ & $2.00 \pm 0.06 \mathrm{~b}$ & $<0.001$ \\
\hline Total protein g/dl & $8.41 \pm 0.09 \mathrm{a}$ & $6.30 \pm 0.10 \mathrm{~b}$ & $<0.001$ \\
\hline Albumin g/dl & $4.09 \pm 0.10 \mathrm{a}$ & $2.63 \pm 0.07 \mathrm{~b}$ & $<0.001$ \\
\hline Glucose mg/dl & $78.48 \pm 0.68 \mathrm{a}$ & $50.10 \pm 0.56 \mathrm{~b}$ & $<0.001$ \\
\hline Urea mg/dl & $27.66 \pm 0.53 \mathrm{~b}$ & $45.59 \pm 1.29 \mathrm{a}$ & $<0.001$ \\
\hline Creatinine mg/dl & $1.01 \pm 0.04 \mathrm{~b}$ & $1.94 \pm 0.05 \mathrm{a}$ & $<0.001$ \\
\hline Total bilirubin mg/dl & $0.77 \pm 0.03 \mathrm{~b}$ & $2.42 \pm 0.09 \mathrm{a}$ & $<0.001$ \\
\hline Alp U/l & $103.83 \pm 3.14 \mathrm{~b}$ & $201.68 \pm 4.96 \mathrm{a}$ & $<0.001$ \\
\hline
\end{tabular}

-Values with different superscript letters within the same row were statistically significant at $p<0.05$. 

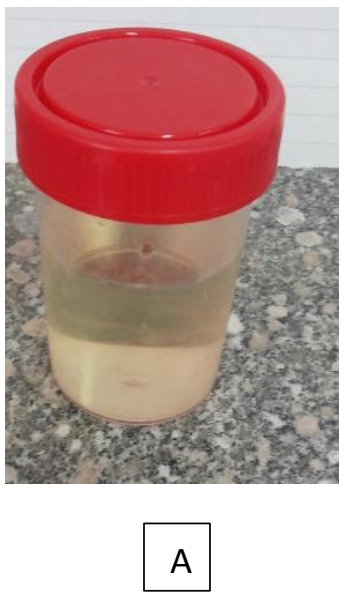

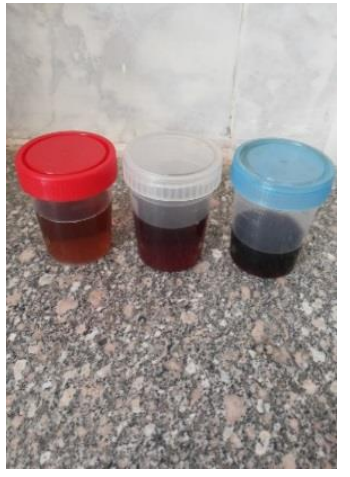

B
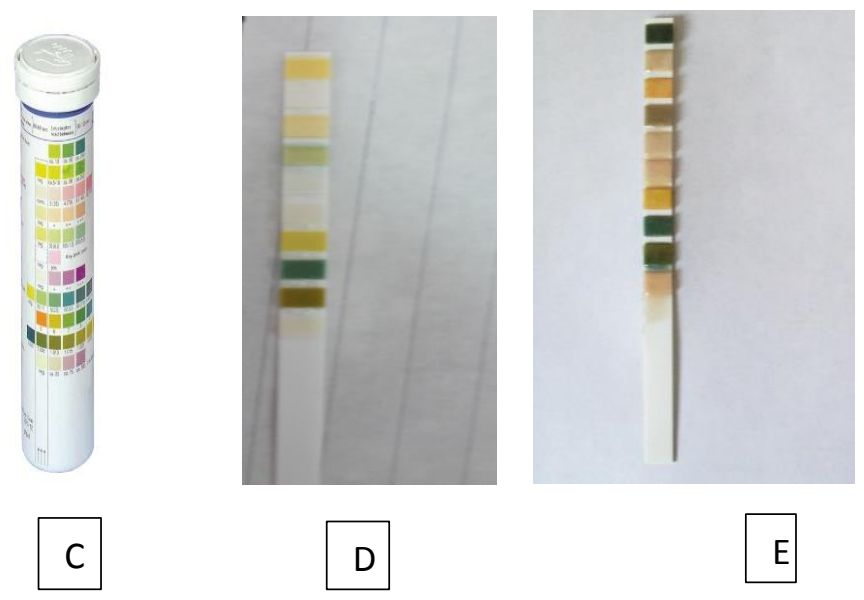

Fig.1:
(A) Urine sample with normal colour of control buffaloes.
(B) Urine samples colour ranged from red, dark red to coffee colour of PPH buffaloes.
(C) Urine strips.
(D) Urine strip showed no change in the parameters of control buffaloes.
(E) Urine strip showed changes in urine samples of PPH buffaloes.

\section{DISCUSSION}

Phosphorus is necessary for glycolysis, the formation of adenosine-triphosphate, and is also required for the maintenance of the erythrocyte cell membranes. Low serum inorganic phosphorus is a frequent finding in cattle with PPH, McCaughan (1993).

PPH affected buffaloes showed significant decrease in total erythrocyte count, $\mathrm{Hb}$ concentration, and haematocrit which indicates severe anaemia. This could be attributed to intravascular haemolysis due to an impaired glycolytic pathway and depletion of ATP in erythrocytes, which results from phosphorus deficiency. Subnormal concentration of ATP predisposes red blood cells to alter functions and structure, a loss of normal formability and an increase in fragility, ultimately leading to haemolysis. The obtained results were nearly agreeable with that reported by Akhtar et al., (2007).

In PPH affected buffaloes, we obtained variation in neutrophils and lymphocyte, which attributed to the endogenous release of corticosteroids. Increased stress due to PPH (a metabolic disorder) is the source of the release of corticosteroids that results in increased neutrophils and depressed lymphocytes. These findings coincided with Sarma et al., (2014).

In addition, the serum inorganic phosphorus was significant decreased in $\mathrm{PPH}$ affected buffaloes. These results were agreed with Khan and Akhtar (2007). In advanced gestation, more phosphorus and calcium are required for the developing fetus if supplementary phosphorus is not provided, thereby leading to hypophosphatemia. Moreover, 
high calcium to phosphorus ratio results in decreased phosphorus absorption from the intestinal tract and ultimately leads to hypophosphatemia, (Digraskar et al., 1991).

Fodders grown on soils deficient in phosphorus are consequently low in phosphorus content and, therefore, prolonged feeding on such fodders can lead to hypophosphatemia, Radostits et al., (2000).

Heavy dependence on phosphorus deficient forage during periods of high physiological demand is suspected as probable predisposing factor for hypophosphatemia Wakayo et al., (2013).

phosphorus deficiency can reduce the adenosine triphosphate content in red blood cells, influencing the structure and function of the cell, thereby increasing fragility and haemolysis, which may lead to acute haemoglobinuria Wang et al., (1985).

Moreover, PPH affected buffaloes showed decrease total protein, albumin and glucose levels. These findings were coincided with those reported by Ghanem and El-Deeb (2010). Total protein and albumin are synthesized by the liver, decreased serum, total protein and albumin may result from liver dysfunction. It can also result from kidney disease, which allows proteins to escape into the urine (Golab et al., 2011).

Higher blood urea and creatinine levels in PPH affected buffaloes, these results were agreeable with Akhtar et al. (2007) which could be attributed to the endogenous release of corticosteroids, starvation, and tubular epithelial necrosis. Additionally, dehydration usually occurs with PHH affected buffaloes, which is a source of decreased renal perfusion, resulting in a reduced glomerular filtration rate and increased blood urea and creatinine levels.

Serum total bilirubin level significantly increase in post parturient haemoglobinuria affected buffaloes, this finding in the line with Akhtar et al. (2008) which could be due to increased destruction of erythrocytes (haemolysis), hepatocellular damage and anorexia/dehydration.

Increase serum ALP concentration in post parturient haemoglobinuria affected buffaloes, this coincided with Cornelius, (1980) which could be attributed to the drastic fall in haemoglobin levels as a result of intravascular haemolysis which creates generalized hypoxia, cause damage to cell membranes, resulting in leakage of ALP.

The colour of urine in post parturient haemoglobinuria affected buffaloes ranged from red, dark red to coffee colour, depending upon the severity and duration of illness. Urinalysis of PHH affected buffaloes in the present study revealed presence of haemoglobin and proteins, and absence of glucose, ketone bodies and leucocytes. The obtained results were agreed with Sateesh et al. (2017).

\section{CONCLUSION}

From the previous obtained results, we concluded that PPH produced significant changes in hematobiochemical and urological parameters in

buffaloes.

\section{REFREENCES}

Akhtar, M. Z.; Khan, A.; Sarwar, M. and Javaid, A. (2007): Influence of Soil and Forage Minerals on Buffalo (Bubalus bubalis) 
Parturient Haemoglobinuria. Asian-Aust. J. Anim. Sci. 20(3) Pp: 393 - 398.

Akhtar, M.Z.; Khan, A. and Javaid, A. (2008): Patho-biochemical changes in buffaloes (Bubalus bubalis) suffering from parturient haemoglobinuria. Pakistan Vet. J. 28(3) Pp: 139-143.

Anderson, S. C. and Cockayne, S. (1993): Clinical chemistry concepts and applications. W.B. Saunders Company, Philadelphia, London, Toronto, Montreal, Sydney, Tokyo. Pp:429-482.

Bailey, R. A. (2008): Design of Comparative Experiments. Cambridge University Press. Pp:116-128.

Benjamin, M. M. (1978): Outline of Veterinary Clinical Pathology. 3rd Ed., Iowa State Univ. Press, Ames, Iowa, USA.

Chugh, S. K.; Mata, M. M. and Malik, K. S. (1996): Epidemiological observations on post-parturient haemoglobinuria in buffaloes. Indian J. Anim. Sci. (66) Pp: 1123-1125.

Constable, P. D.; Hinchcliff, K. W.; Done,S. H. and Grünberg, W. (2017): Veterinary Medicine, $11^{\text {th }}$ Ed. Elsevier Ltd. Riverport Lane, St. Louis, Missouri.

Cornelius, C.E. (1980): Liver Functions. In Kaneko, J.J. (ed.) Clinical Biochemistry of Domestic Animals 3rd ed. Academic Press, Inc. New York, USA.

Digraskar, S.; Singh, B. and Deshpande, B.B. (1991): Epidemiology and clinico-pathology of haemoglobinuria in buffalo (Bubalus bubalis). Livest. Advisor. (16) Pp: 32-38.

Fischbach, F. T. and Dunning, M. B. (2009): Manual of Laboratory and Diagnostic Tests, 8th Ed. Philadelphia: Lippincott Williams and Wilkins.

Ghanem, M. M. and El-Deeb, W. M. (2010): Lecithin cholesterol acyltransferase (LCAT) activity as a predictor for ketosis and parturient haemoglobinuria in Egyptian water buffaloes. Research in Veterinary Science (88) Pp.: 20-25.

Golab, H. D.; Scohy, T. V.; de Jong, P. L.; Kissler, J.; Takkenberg, J. J. M. and Bogers, J. J. C. (2011): Relevance of colloid oncotic pressure regulation during neonatal and infant cardiopulmonary bypass: a prospective randomized study. European Journal of Cardiothoracic Surgery. (39) pp: 886-891.

Kaneko, J.J.; Harvey, J.W. and Bruss, M.L. (1997): Clinical biochemistry of domestic animals, $5^{\text {th }}$ ed., Academic Press, San Diego.

Kelly, W. R. (1984): The abdominal and associated digestive organs. In: Vet. Clini. diagnosis. Bailliere Tindall, London.

Khan, A. and Akhtar, M. Z. (2007): Hematobiochemical and clinico-epidemiological aspects of parturient haemoglobinuria in Nili-Ravi buffaloes. Ital. J. anim. Sci. 6 (2) Pp: 953-956.

Mahmood, A. (2011): Epidemiological, haematological and biochemical risk factors of parturient haemoglobinuria in buffaloes. Faculty of veterinary science university of veterinary and animal sciences, Lahore.

McCaughan, C.J. (1993): Post parturient haemoglobinuria. In: Current Veterinary Therapy 3. Food Animal Practice. Edited by J.L. Howard Harcourt Brace Jovanovich Inc., Philadelphia. Pp: 323-326. 
NRC (National Research Council) (2001): Nutrient Requirements of Dairy Cattle, $7^{\text {th }}$ ed. National Academy Press, Washington, DC.

Pagana, K. D. and Pagana, T. J. (2010): Mosby's Manual of Diagnostic and Laboratory Tests ( ${ }^{\text {th }}$ Ed.). St. Louis: Mosby/Elsevier.

Patton, C. J. and Crouch, S. R. (1977): Enzymatic determination of urea. Anal.Chem. (49) Pp:464-469.

Radostits, O.M.; Gay, C.C.; Blood, D.C. and Hinchcliff, K.W. (2003): Veterinary Medicine: A Textbook of the Diseases of Cattle, Sheep, Pigs, Goats and Horses, 10th ed. W.B. Saunders, London, UK.

Radostits, O.M.; Gay, C.C.; Blood, D.C. and Hinchcliff, K.W. (2000): Veterinary Medicine: A Textbook of the Diseases of Cattle, Sheep, Pigs, Goats and Horses, 9th Ed. W.B. Saunders, London.

Sarma, K.; Saravanan, M.; Kumar, P.; Kumar, M.; Jadav, R.K. and Mondal, D.B. (2014): Influence on haemato-biochemical and oxidative indices of post parturient haemoglobin uric (PHU) buffalo. Buffalo Bulletin. 33(4).

Sateesh, A.G.; Roopali, B.; Ravindra, B.G.; Arunkumar; Abhilash, B. and Dhabale, R.B. (2017): A study on comparison of haematobiochemical changes in haemoglobinuria buffaloes. The Pharma Innovation Journal; 6(11) Pp: 125-128.

Ternouth, J.H. (1990): Phosphorus and beef production in Northern Australia. 3. Phosphorus in cattle - a review. Tropical Grassland. (24) Pp:159-169.

Thrall, M.A.; Weiser, G.; Allison, R. and Campbell, T.W. (2012): Veterinary hematology and clinical chemistry. John Wiley and Sons.

Trinder, P. (1969): Determination of glucose in blood using glucose oxidase with on alternative oxygen receptor. Ann Clin. Biochem. (6) Pp: 24-27.

Wakayo, B.U.; Vaungahun, E. and Brar, P.S. (2013): Diagnosis and Treatment of Post parturient Haemoglobinuria in Buffalo; A Case Report. Guru Angad Dev Veterinary and Animal Science University, Department of Veterinary Gynaecology and Obstetrics, Ludhiana 141 004, Punjab, India.

Wang, X.L.; Gallager, C.H.; Mcclure, T.J.; Reeve, V.E. and Canfield, P.J. (1985): Postparturient haemoglobinuria: effect of inorganic phosphate on red cell metabolism. Research Veterinary Science. (39) pp: 333339.

Young, D. S. (1990): Effect of drugs on clinical Laboratory tests. $3^{\text {rd }}$ Ed., AACC Press, Washington, D.C. Pp: 3122-3131. 